\title{
Coliformes totais e Escherichia coli em coxas de frango comercializados no Rio de Janeiro
}

\section{Total coliforms and Escherichia coli chicken thigh commercialized in Rio de Janeiro}

\author{
Analy Machado de Oliveira Leite, ${ }^{*}$ Robson Maia Franco**
}

\begin{abstract}
Resumo
Os objetivos deste trabalho foram enumerar coliformes totais e Escherichia coli, que é um indicador de contaminação fecal, comparando os resultados obtidos frente aos padrões de identidade e qualidade nacionais vigentes, além de realizar a sorologia das cepas de E. coli isoladas em coxas de frango, obtidas em estabelecimentos com e sem inspeção sanitária, comercializadas no município do Rio de Janeiro. Para enumeração dos microrganismos foi utilizada metodologia miniaturizada com meios de cultura de rápida detecção, contendo indicadores fluorogênicos e cromogênicos. Das 30 amostras analisadas, 12 apresentaram número mais provável (NMP) de E. coli variando de $<3$ a 2,9x107/g, sendo seis $(20 \%)$ consideradas impróprias para o consumo de acordo com a legislação vigente. Das 150 colônias suspeitas e confirmadas em testes bioquímicos 18 (12\%) foram positivas para os sorogrupos E. coli enteropatogênica (EPEC) e E. coli enteroinvasiva (EIEC), provenientes de 15 amostras diferentes. Das 17 colônias suspeitas para E. coli enterohemorrágica (EHEC), nenhuma cepa pertencia a este grupo. Os resultados indicam que a existência de um serviço de inspeção eficiente, em todas as fases do processo tecnológico do frango, é muito importante para obtenção de um produto de qualidade e seguro, sem riscos para a saúde do consumidor.
\end{abstract}

Palavras-chave: carne de frango, qualidade bacteriológica, detecção rápida, coliformes totais, Escherichia coli.

\begin{abstract}
The objectives of this work were to enumerate total coliforms and Escherichia coli, that is indicators of fecal contamination, comparing the achieved results with the current standards of national identity and quality, and also to perform the serological confirmation of isolated strains $E$. coli in chicken thigh, obtained in establishments with and without sanitary inspection, commercialized in the city of Rio de Janeiro. In the enumeration of the microorganisms, the miniaturized methodology was performed with culture media for rapid detection, based in fluorogenic and chromogenic substrates in their composition. Twelve of the 30 analyzed samples presented most probable number (MPN) of $E$. coli varying from $<3$ to $2.9 \times 10^{7} / \mathrm{g}$, with six $(20 \%)$ considered improper for human consumption in accordance with the current legislation. From the 150 colonies suspected and confirmed with biochemical tests, $18(12 \%)$ were tested positive for enteropathogenic $E$. coli (EPEC) and enteroinvasive E. coli (EIEC), taken from 15 different samples. From 17 colonies suspected for enterohaemorrhagic $E$. coli (EHEC), no strain belonged to this group. The results indicate that the existence of a service of efficient inspection, in all the stages of the technological process of the poultry, is very important to supply a product with quality and safety, without risking the health of the consumer.
\end{abstract}

Keywords: chicken meat, bacteriology quality, rapid detection, total coliforms, Escherichia coli.

\section{Introdução}

O avanço da avicultura nas últimas décadas permitiu aumento no consumo per capita da carne de aves no Brasil. Avanços na genética, na nutrição, na disponibilidade de grãos e no manejo posicionou o Brasil entre os principais países que mais produzem e exportam carne de frango no mundo.

Vários fatores que favorecem o consumo da carne de frango, pois além de ser um alimento de alto valor nutritivo, é economicamente acessível, apresenta melhor digestibilidade, menor valor calórico e níveis de colesterol, quando comparadas com as carnes bovinas, sendo recomendada para recuperação de funções fisiológicas de indivíduos imunocomprometidos. Porém, devido à excelente capacidade nutritiva, é um alimento altamente perecível. As bactérias são os principais agentes responsáveis pela deterioração, redução do prazo de vida comercial e pela ocorrência de surtos alimentares.

A Agência Nacional de Vigilância Sanitária (ANVISA), através da Resolução RDC № 12, de 2 de janeiro de 2001 (Brasil,

\footnotetext{
* Discente (Iniciação Científica) - Faculdade de Veterinária, Universidade Federal Fluminense. E-mail: analyleite@yahoo.com.br.

** Departamento de Tecnologia dos Alimentos. Faculdade de Veterinária, Universidade Federal Fluminense - Rua Vital Brazil Filho, 64, CEP 24230-340, Niterói, RJ - Brasil.

Autor para correspondência: Robson Maia Franco. E-mail: robsonmf@vm.uff.br.
} 
2001), exige a enumeração de coliformes termotolerantes como prova analítica para liberação de carnes de aves para consumo.

O grupo coliformes totais é composto por bactérias da família Enterobacteriaceae, capaz de fermentar a lactose com produção de gás, quando incubados a $35-37^{\circ} \mathrm{C}$, por 48 horas. São bacilos Gram-negativos, não formadores de esporos e inclui cerca de 20 espécies, dentre as quais encontram-se tanto bactérias originárias do trato gastrintestinal de humanos e outros animais de sangue quente, como também diversos gêneros e espécies de bactérias não-entéricas, como Serratia spp. e Aeromonas spp.

A E. coli faz parte da microbiota intestinal normal, é um bastonete Gram-negativo, não esporulado, oxidase negativa, móvel por flagelos peritríquios ou não-móvel, anaeróbio facultativo capaz de fermentar a glicose e a lactose produzindo ácido e gases. Dentre as bactérias de habitat reconhecidamente fecal, $E$. coli é a mais conhecida e mais facilmente diferenciada dos membros não fecais.

Outro aspecto, é que diversas linhagens de Escherichia coli são comprovadamente patogênicas para o homem e animais, podendo provocar infecções graves, levando os pacientes ao óbito e, portanto, reduzidas quantidades, geralmente aceitáveis, adquirem novo significado, em especial quando as condições do alimento em que se encontra permitem sua multiplicação (Franco, 2002). Essas cepas patogênicas são classificadas de acordo com sua ação no hospedeiro. As categorias que causam infecção intestinal são coletivamente chamadas de E. coli diarreiogênicas, podendo ser: E. coli enteropatogênica clássica (EPEC), enterotoxigênica (ETEC), enteroinvasora (EIEC), êntero-hemorrágica (EHEC) e enteroagregativa (EAEC).

O método tradicional da técnica de tubos múltiplos para detecção de coliformes totais, fecais é laborioso e demorado, pois envolve várias etapas presuntiva e confirmativa, levando no mínimo 48 horas para identificação presuntiva. Recentemente, novos métodos vêm sendo desenvolvidos como forma alternativa para os métodos convencionais, baseados na tecnologia de substratos específicos marcados com indicadores cromogênicos e/ou fluorogênicos. A incorporação desses substratos em um meio seletivo pode eliminar a necessidade de subcultivos e posteriores testes bioquímicos para identificação de certos microrganismos (Manafi, 2000).

Este trabalho tem como objetivo enumerar coliformes totais e E. coli em amostras de carne de frango e comparar os resultados obtidos frente aos padrões de identidade e qualidade nacionais vigentes constantes da Resolução RDC no 12 (Brasil, 2001), além de realizar a sorologia das cepas de $E$. coli isoladas.

\section{Material e métodos}

Foram analisadas trinta amostras de coxas de frango: 15 obtidas em cinco abatedouros e 15 obtidas em cinco supermercados do município do Rio de Janeiro. Todas foram transportadas sob refrigeração até o Laboratório de Controle Microbiológico de Produtos de Origem Animal (P.O.A.) do Departamento de Tecnologia dos Alimentos da Faculdade de Veterinária da Universidade Federal Fluminense, para a realização do procedimento analítico.
No preparo das amostras para a enumeração de coliformes totais e Escherichia coli, foram pesados $25 \mathrm{~g}$ de cada amostra e homogeneizados em $225 \mathrm{~mL}$ de solução salina peptonada a $0,1 \%$ (SSP), para posterior realização das diluições seriadas, que foram realizadas utilizando a técnica de miniaturização dos procedimentos convencionais. Esta técnica descrita por Cox et al. (1984), oferece muitas vantagens, entre as quais: aperfeiçoamento da amostragem; economia de meios de cultivo; redução do tempo no preparo das diluições; economia financeira sem afetar a seletividade, a especificidade e o coeficiente global da metodologia tradicional.

As diluições foram inoculadas (100 ml) em três séries de três eppendorfs contendo (1000 ml) meio Fluorocult LMX (MERCK, 2000), com incubação a $35^{\circ} \mathrm{C} / 24-48$ horas. Os cultivos verdes azulados indicam a presença de coliformes totais, pois estes produzem a enzima â-galactosidase que cliva o substrato "XGAL" do meio. Os cultivos positivos azuis claros fluorescentes (reação MUG) sob luz ultravioleta 366 nm, indicam a presença de E. coli (coliforme fecal), confirmadas através da adição do reativo de Kovacs, que ao formar um anel vermelho indicava presença de indol. O cálculo do NMP dos coliformes foi efetuado pela tabela de Mac Crady, entretanto, multiplicados por 10, pois os inóculos foram 10 vezes menores.

A metodologia para o isolamento e identificação de cepas $E$. coli foi realizada de acordo com as técnicas de Meng et al. (2001). Foi incubado à $35^{\circ} \mathrm{C}$ por 3 horas, $10 \mathrm{~g}$ da amostra com $90 \mathrm{~mL}$ de caldo Brain Hearth Infusion (BHI) e em seguida o inóculo foi semeado em $90 \mathrm{~mL}$ de caldo triptona fosfato $\left(44^{\circ} \mathrm{C} /\right.$ 20 horas). Os subcultivos foram semeados em placas com ágar Mac Conkey, ágar Salmonella-Shigella e ágar Eosina Azul de Metileno - EMB $\left(35^{\circ} \mathrm{C} / 24\right.$ horas $)$. Duas unidades formadoras de colônias (UFC) típicas foram selecionadas e a triagem realizada em ágar SIM e Citrato $\left(35^{\circ} \mathrm{C} / 24\right.$ horas); as colônias suspeitas de $E$. coli foram semeadas em ágar EPM (Toledo et al., 1982a) e MILI (Toledo et al., 1982b) e incubadas a $35^{\circ} \mathrm{C}$ por 24 horas. As confirmadas como $E$. coli foram estocadas em caldo $\mathrm{BHI}$ a $4^{\circ} \mathrm{C}$, para posterior sorologia.

Para o isolamento, identificação de E. coli O157:H7 e diferenciação de cepas êntero-hemorrágicas, foram pesados 10 gramas da amostra e homogeneizados em $90 \mathrm{~mL}$ de caldo Lauril Sulfato e incubados à $35^{\circ} \mathrm{C} / 24$ horas. Os subcultivos foram semeados em ágar Fluorocult E. coli O157:H7, ágar Mac Conkey Sorbitol $\left(35^{\circ} \mathrm{C} / 24\right.$ horas). Duas UFC suspeitas de EHEC, foram repicadas para o meio SIM e ágar Citrato e posterior semeadura em ágar MILI e EPM.

A sorologia para Escherichia coli foi realizada em todos os cultivos estocados e confirmados bioquimicamente para $E$. coli. Todas as colônias positivas na soroaglutinação com os anti-soros polivalentes (Probac do Brasil LTDA), foram testadas, com os anti-soros monovalentes correspondentes. Para a soroaglutinação em placa seguiu-se metodologia descrita por Ewing (1986).

\section{Resultados e Discussão}

Conforme resultados encontrados no método I (Tabela 1), a média do NMP de E. coli foi $9,8 \times 10^{5} / \mathrm{g}$, variando de $<3$ a $2,9 \times 10^{7} / \mathrm{g}$, ocorrendo em 12 amostras (40\%). Na contagem de coliformes totais, a média foi $2,0 \times 10^{7} / \mathrm{g}$ com valores variando de $<3$ 
coliformes totais/g a $>2,4 \times 10^{8} / \mathrm{g}$, sendo que somente uma $(3,33 \%)$ apresentou o menor valor.

Tabela 1: Resultados das análises de coliformes totais e $E$. coli pelo método 1, de amostras de coxas de frango resfriadas

\begin{tabular}{|c|c|c|c|}
\hline Amostra & Origem & $\begin{array}{c}\text { Coliformes } \\
\text { Totais (NMP/g) }\end{array}$ & E. coli $(\mathrm{NMP} / \mathrm{g})$ \\
\hline 1 & Trailer & $1,1 \times 10^{5}$ & $2,4 \times 10^{4}$ \\
\hline 2 & Aviário & $2,3 \times 10^{3}$ & $2,3 \times 10^{3}$ \\
\hline 3 & Supermercado & $4,0 \times 10^{3}$ & $<3,0$ \\
\hline 4 & Supermercado & $<3,0$ & $<3,0$ \\
\hline 5 & Supermercado & $2,7 \times 10^{4}$ & $<3,0$ \\
\hline 6 & Açougue & $>1,1 \times 10^{6}$ & $<3,0$ \\
\hline 7 & Supermercado & $4,3 \times 10^{3}$ & $9,0 \times 10^{2}$ \\
\hline 8 & Supermercado & $4,0 \times 10^{2}$ & $<3,0$ \\
\hline 9 & Supermercado & $1,1 \times 10^{4}$ & $7,0 \times 10^{3}$ \\
\hline 10 & Supermercado & $3,5 \times 10^{4}$ & $1,1 \times 10^{4}$ * \\
\hline 11 & Trailer & $2,1 \times 10^{8}$ & $2,9 \times 10^{7}$ * \\
\hline 12 & Açougue & $1,1 \times 10^{5}$ & $9,3 \times 10^{4}$ * \\
\hline 13 & Açougue & $1,1 \times 10^{7}$ & $2,9 \times 10^{5}$ * \\
\hline 14 & Supermercado & $4,0 \times 10^{3}$ & $<3,0$ \\
\hline 15 & Supermercado & $>1,1 \times 10^{6}$ & $<3,0$ \\
\hline 16 & Açougue & $>1,1 \times 10^{7}$ & $<3,0$ \\
\hline 17 & Supermercado & $2,4 \times 10^{8}$ & $<3,0$ \\
\hline 18 & Açougue & $6,2 \times 10^{2}$ & $<3,0$ \\
\hline 19 & Feira & $2,4 \times 10^{5}$ & $4,3 \times 10^{3}$ \\
\hline 20 & Supermercado & $2,3 \times 10^{3}$ & $<3,0$ \\
\hline 21 & Supermercado & $4,3 \times 10^{4}$ & $<3,0$ \\
\hline 22 & Supermercado & $1,5 \times 10^{4}$ & $<3,0$ \\
\hline 23 & Supermercado & $2,8 \times 10^{4}$ & $2,3 \times 10^{3}$ \\
\hline 24 & Feira & $2,0 \times 10^{5}$ & $9,3 \times 10^{3}$ \\
\hline 25 & Feira & $>1,1 \times 10^{8}$ & $9,3 \times 10^{3}$ \\
\hline 26 & Supermercado & $2,9 \times 10^{5}$ & $<3,0$ \\
\hline 27 & Aviário & $2,4 \times 10^{7}$ & $4,3 \times 10^{4}$ * \\
\hline 28 & Aviário & $4,0 \times 10^{2}$ & $<3,0$ \\
\hline 29 & Feira & $2,4 \times 10^{5}$ & $<3,0$ \\
\hline \multirow[t]{2}{*}{30} & Açougue & $9,3 \times 10^{3}$ & $<3,0$ \\
\hline & Média & $2,0 \times 10^{7}$ & $9,8 \times 10^{5}$ \\
\hline
\end{tabular}

${ }^{*} \mathrm{NMP} / \mathrm{g}$ acima do limite permitido para o consumo

Mantilla et al. (2004), utilizaram a mesma metodologia para enumeração de coliformes totais e E. coli deste trabalho, e constaram se tratar de um método confiável e eficaz, por não apresentar resultado falso negativo, com a vantagem de ser facilmente utilizado e requerer tempo menor que a convencional. Gleissler et al. (2000); Suwansonthichai e Rengpipat (2003) compararam a eficiência destes métodos rápidos com os convencionais em amostras de água do mar e camarão, respectivamente, e concluíram que o meio LMX é sensível e específico na determinação de E. coli, sendo uma alternativa apropriada na enumeração deste microrganismo.

Além dos coliformes totais oriundos de ambientes não-fecais, a presença de $E$. coli indica contaminação de origem fecal na produção, processamento, armazenamento inadequado das amostras e/ou falta de higiene dos manipuladores, podendo indicar presença de enteropatógenos e deterioração potencial do alimento. Das 13 amostras positivas para $E$. coli, nove $(69 \%)$ foram adquiridas em abatedouros clandestinos, evidenciando que os cuidados com as práticas higiênicas muitas vezes são negligenciados, confirmando o perigo da comercialização desta carne e a necessidade de uma inspeção sanitária eficiente.
Dentre as amostras analisadas, 24 (80\%) enquadraram-se nos padrões de qualidade e identidade da legislação vigente, consideradas próprias para o consumo. Enquanto que seis (20\%), obtiveram contagem de E. coli superior ao estabelecido pelo padrão $\left(10^{4}\right)$, sendo cinco delas $(83 \%)$, provenientes de abatedouros sem inspeção. Delú et al. (2006), avaliaram as condições higiênico-sanitárias de trinta amostras de cortes de frango resfriados, comercializados em dez estabelecimentos diferentes de Minas Gerais e revelaram que $100 \%$ das amostras estavam contaminadas com coliformes totais e fecais, porém dentro dos padrões estabelecidos pela legislação. Cardoso et al. (2005) também avaliaram a qualidade microbiológica de 29 carcaças e 35 cortes de frango oriundos de abatedouros avícolas de São Paulo, e os valores do NMP para coliformes fecais por grama de amostra obtida foram mais baixos que o presente trabalho, todas consideradas próprias para o consumo.

Na sorologia, das 150 colônias suspeitas e confirmadas em testes bioquímicos (método II), 18 (12\%) foram positivas para os sorogrupos EPEC e EIEC. Nove cepas (50\%) eram provenientes de oito (53\%) amostras adquiridas em supermercados e nove cepas $(50 \%)$ provenientes de sete (47\%) amostras adquiridas em abatedouros sem inspeção. Conforme disposto na Tabela 2, para o grupo de amostras com inspeção sanitária, seis colônias $(66,7 \%)$ isoladas estavam contaminadas por EPEC e para EIEC três (33,3\%) colônias. Para o grupo de amostras sem inspeção sanitária foram encontradas sete colônias (77,8\%) contaminadas por EPEC e para EIEC duas $(22,2 \%)$ colônias.

Tabela 2: Resultado dos testes sorológicos das cepas E. coli isoladas de amostras de coxas de frango resfriadas

\begin{tabular}{|c|c|c|c|c|c|}
\hline \multirow[t]{2}{*}{ Amostras } & \multicolumn{5}{|c|}{ Sorogrupos } \\
\hline & EPEC A & EPEC B & EPEC C & EIEC A & Total \\
\hline \multirow{3}{*}{$\begin{array}{l}\text { Com } \\
\text { inspeção }\end{array}$} & O119(2) & O114 (1) & - & O136(1) & \\
\hline & $N T^{*}(1)$ & 0125 (1) & & O152(1) & \\
\hline & & $N T^{*}(1)$ & & $\mathrm{O} 28 \mathrm{ac}(1)$ & \\
\hline \multirow{3}{*}{$\begin{array}{l}\text { Sem } \\
\text { inspeção }\end{array}$} & O119(2) & \multirow[t]{3}{*}{ O114(1) } & O126(1) & O29(1) & \\
\hline & O111(1) & & O128(1) & $\mathrm{O} 28(1)$ & \\
\hline & $N T^{*}(1)$ & & & & \\
\hline Total & \multicolumn{3}{|c|}{$13(72,2 \%)$} & $5(27,8 \%)$ & $18(100 \%)$ \\
\hline
\end{tabular}

*Não Tipável

Na caracterização sorológica de cepas isoladas de cortes de carne bovina comercializadas no Rio de Janeiro, realizada por Mantilla et al. (2004), todas as amostras foram positivas para sorogrupos EPEC e EIEC, sendo que a classe EPEC foi encontrada em maior porcentagem (94,7\%). Apesar de 100\% das cepas isoladas nas amostras de alimentos analisadas, pertencerem sorologicamente, a alguma classe de E. coli patogênica, estes resultados são similares com os mesmos deste trabalho, onde a classe EPEC prevalece $(72,2 \%)$, conforme também descrito por Silva et al. (2001), em que analisaram amostras de leites pasteurizados no Brasil, e cepas do sorogrupo EPEC também foram predominantes $(22,1 \%)$. Estes dados são corroborados com a afirmação de Franco e Landgraf (1996) quando ressaltam que EPEC está entre os principais agentes enteropatogênicos, com coeficientes de mortalidade altos, nos países menos desenvolvidos, e que no Brasil, é responsável por cerca de $30 \%$ dos casos de diarréia aguda em recém-nascidos e lactentes. 
Embora estudos recentes, como de Carneiro et al. (2006), sobre fatores de virulência indicarem que nem todas as cepas sorogrupadas entre as classes patogênicas de E. coli possuírem a capacidade de causar doença, considerou-se de extrema importância o isolamento e identificação destes sorogrupos na carne de frango, pois podem representar um risco potencial para crianças e atuar como veículo para transmissão de E. coli diarreiogênicas no Brasil.

Com a realização do método III, das 17 colônias isoladas e suspeitas de pertencerem ao grupo de EHEC, não foi encontrada nenhuma cepa positiva para sorogrupo O157:H7. Estes dados assemelham-se com obtidos anteriormente por Cerqueira et al. (2005) que indicaram ausência de E. coli 0157:H7 em produtos avícolas. Manafi e Kremsmaier (2001), compararam diferentes meios de cultura fluorogênicos para detecção de E. coli O157:H7 com o ágar convencional Mac Conkey Sorbitol e relataram que na análise de amostras de alimentos, o ágar Mac Conkey Sorbitol apresentava 57,3\% de resultados falso positivos, enquanto que o ágar Fluorocult O157:H7 6,2\%, indicando comportamento insatisfatório do ágar convencional. Além disso, nenhuma amostra apresentou resultado positivo para este sorogrupo, resultado similar ao

\section{Referências}

BRASIL. Ministério da Saúde. Agência Nacional de Vigilância Sanitária. Resolução RDC no 12 de 2 de janeiro de 2001. Regulamento técnico sobre padrões microbiológicos para alimentos e seus Anexos I e II. Diário Oficial [da] República Federativa do Brasil, Brasília, DF, jan. 2001. Seção 1, p. 54.

CARDOSO, A.L.S.P.; CASTRO, A. G. M.; TESSARI, E. N. C.;BALDASSI, L., PINHEIRO, E. S. Pesquisa de Salmonella spp., coliformes totais, coliformes fecais, mesófilos, em carcaças e cortes de frango. Higiene Alimentar, São Paulo, v. 19, n. 128, p. 144-150, 2005.

CARNEIRO, L. A.M.; LINS, M.C.; GARCIA, F.R.A.; SILVA, A.P.S.; MAULLER, P.M.; ALVES, G.B.;ROSA, A.C.P.;ANDRADE,J.R.C.; FREITASALMEIDA, A.C.; QUEIROZ, M.L.P. Phenotypic and genotypic characterisation of Escherichia coli strains serogrouped as enteropathogenic E. coli (EPEC) isolated from pasteurised milk. International Journal of Food Microbiology. v. 108, p. 15-21, 2006.

CERQUEIRA, A. M. F.; GUIMARAES, C.M.; DIAS, M. T.; PEREIRA, K. S. Ocorrência de Escherichia coliprodutora de toxina Shiga em produtos cárneos crus industrializados de aves (hambúrguer de frango e peru). SEMINÁRIODE INICIAÇÃOCIENTÍFICAEPRÊMIOUFFVASCONCELLOS TORRES DE CIÊNCIA E TECNOLOGIA, 15., 2005. Niterói, RJ. Anais...Niterói: Universidade Federal Fluminense, 2005.1 CD.

COX, N.A.;FUNG, D.Y.C.; GOLDSCHIMIDT,M.C.;BALEY,J.S.;THOMSON, J.E. Selecting a miniaturized system for identification of Enterobacteriaceae. Journal Food Protection, v. 47, p. 74-77, 1984.

DELÚ, M. A. F.; SHAMPATO, C. G.; MENDONÇA, A. T.; PICCOLI, R. H.; MAIA, S. C. Avaliação Microbiológica de cortes de frango resfriado, comercializados no município de lavras, MG. Higiene Alimentar, São Paulo, v. 20, n. 138, p. 83-85, 2006.

EWING, W.A. Edward's, Ewing's Identification of Enterobacteriaceae. 4 th ed., Elsevier Science Publishers, New York, p. 93-134, 1986.

FRANCO, B.D.G.M.; LANDGRAF, M. Microbiologia de Alimentos, São Paulo: Atheneu, 1996. $182 \mathrm{p}$.

FRANCO, R.M. Escherichia coli: ocorrência em suínos abatidos do Grande Rio e sua viabilidade experimental em lingüiça frescal, tipo toscana. $2002.153 \mathrm{f}$. Tese (Doutorado em Medicina Veterinária) Faculdade de Veterinária, Universidade Federal Fluminense, 2002. deste trabalho. Segundo Vernozy-Rozand (1997), devido às baixas doses infectantes de E. coli O157:H7 e baixos níveis naturalmente presentes nos alimentos, meios de enriquecimento e ágar seletivos são essenciais para detecção deste sorogrupo, além de sua confirmação através de provas bioquímicas, imunológicas e/ou PCR.

\section{Conclusão}

O método miniaturizado de detecção rápida, contendo meios de cultura fluorogênicos e cromogênicos, mostrou-se eficaz, rápido e sensível na enumeração e detecção de coliformes totais e E. coli.

Em relação aos limites estabelecidos pela legislação vigente, as amostras provenientes de estabelecimentos sem inspeção, representaram a maior parte das consideradas impróprias para o consumo, servindo como um alerta às autoridades sanitárias, motivo para maior fiscalização aos estabelecimentos, principalmente sobre os clandestinos.

Entretanto, na análise qualitativa, amostras de ambos os grupos, apresentaram cepas sorogrupadas entre classes de E. coli patogênicas, podendo representar um risco potencial aos consumidores.

GLEISSLER, K.; MANAFI, M.; AMORÓS, I.; ALONSO, J.L. Quantitative determination of total coliforms and Escherichia coli in marine waters with chromogenic and fluorogenic media. Journal of Applied Microbiology. v. 88, p. 280-285, 2000.

MANAFI, M. New developments in chromogenic and fluorogenic culture media. International Journal of Food Microbiology, v. 60, p. 205-218, 2000.

MANAFI, M.; KREMSMAIER, B. Comparative evaluation of different Chromogenic fluorogenic media for detecting Escherichia coliO157:H7 in food. International Journal of Food Microbiology. v. 71, p. 257-262, 2001. MANTILLA, S. P.S.; FRANCO, R. M. Escherichia coli em corte de carne bovina: avaliação da metodologia aplicada e sensibilidade antimicrobianados sorovares predominantes. SEMINÁRIO DE INICIAÇÃO CIENTIIFICA E PRÊMIO UFF VASCONCELLOS TORRES DE CIÊNCIAAE TECNOLOGIA, 14., 2004, Niterói, RJ. Anais... Niterói: Universidade Federal Fluminense, 2004. 1 CD.

MENG, J.;FENG, P;DOYLE, P. Pathogenic Escherichia coli. In:DOWNES, F. P.; ITO, K. Compendium of Methods for The Microbiological Examination of Foods. 4. ed. Washington APHA, 2001. 676 p. Cap. 35, p. 331-341.

MERCK. Microbiology Manual. Berlin. Germany:2000. 407 p.

SILVA, Z.N.; CUNHA, A.S.; LINS, M.C.;CARNEIRO, L.A.M.;ALMEIDA, A.C.F.; QUEIROZ, M.L.P. Isolation and serological identification of enteropathogenic Escherichia coli in pasteurized milk in Brazil. Rev. Saúde Pública, v.35, n.4, p.375-379, 2001.

SUWANSONTHICHAI, S.; RENGPIPAT, S. Enumeration of coliforms and Escherichia coli in frozen black tiger shrimp Penaeus monodon by conventional and rapid methods. International Journal of Food Microbiology, v.81, p113-121, 2003.

TOLEDO, M.R.F.; FONTES, C.F.; TRABULSI, L.R. EPM modificação do meio Rugai e Araújo para realização simultânea dos testes de produção de gás a partir da glicose, $\mathrm{H}_{2} \mathrm{~S}$, uréase e triptofano desaminase. Revista de Microbiologia, v. 13, p. 309-315, 1982a.

TOLEDO, M.R.F.; FONTES, C.F.; TRABULSI, L.R. MILI um meio para a realização dos testes de mobilidade, indol e lisina descarboxilase. Revista de Microbiologia, v. 13, p. 230-235, $1982 b$.

VERNOZY-ROZAND, C. Detection of E. coliO157:H7 and $\bullet$. other verocytotoxin-producing $E$. coli VTEC in foods. Journal Applied Microbiology. v. 82, p. 537-551, 1997. 